\title{
Effect of ulinastatin on perioperative organ function and systemic inflammatory reaction during cardiac surgery: a randomized double-blinded study
}

\author{
Jieun Song ${ }^{1}$, Jungmin Park², Jee-Young Kim², Joo-Duck Kim², Woon-Seok Kang ${ }^{2}$, Hasmizy Bin \\ Muhammad $^{2}$, Mi-Young Kwon ${ }^{3}$, Seong-Hyop Kim², Tae Gyoon Yoon ${ }^{2}$, Tae-Yop Kim², and Jin Woo Chung ${ }^{4}$ \\ ${ }^{1}$ Department of Anesthesiology, CHA Bundang Medical Center, CHA University, Seongnam, ${ }^{2}$ Department of Anesthesiology, \\ Konkuk University Medical Center, Research Institute of Biomedical Science, Konkuk University School of Medicine, ${ }^{3}$ Department of \\ Anesthesiology, National Medical Center, ${ }^{4}$ Department of Thoracic Surgery, Konkuk University Medical Center, Konkuk University School \\ of Medicine, Seoul, Korea
}

Background: This study evaluated the efficacy of ulinastatin for attenuating organ injury and the release of proinflammatory cytokines due to cardiopulmonary bypass (CPB) during cardiac surgery.

Methods: Patients undergoing valvular heart surgery employing CPB were assigned to receive either ulinastatin (group $\mathrm{U}, \mathrm{n}=13$ ) or a placebo (group $\mathrm{C}, \mathrm{n}=11$ ) before the commencement of $\mathrm{CPB}$. Hemodynamic data, parameters of major organ injury and function, and proinflammatory cytokines were measured after the induction of anesthesia (T1), after CPB (T2), at the end of anesthesia (T3), and at 24 hours after surgery (POD).

Results: The demographic data, CPB duration, and perioperative transfusions were not different between the groups. $\mathrm{PaO}_{2} / \mathrm{FiO}_{2}$ in group $\mathrm{U}$ was significantly higher than that in group $\mathrm{C}$ at $\mathrm{T} 3(3.8 \pm 0.8$ vs. $2.8 \pm 0.7, \mathrm{P}=0.005)$ and at $\mathrm{POD}(4.0$ \pm 0.7 vs. $2.8 \pm 0.7, \mathrm{P}<0.001)$. Creatine kinase-MB at $\mathrm{POD}$ in group $\mathrm{U}$ was significantly lower than that in group $\mathrm{C}(17.7$ \pm 8.3 vs. $33.7 \pm 22.1, \mathrm{P}=0.03$ ), whereas troponin I at POD was not different between the groups. Creatinine clearance and the extubation time were not different between the groups at POD. The dopamine infusion rate during the postCPB period in group $U$ was significantly lower than that in group C ( $1.6 \pm 1.6 \mathrm{vs.} 5.5 \pm 3.3 \mu \mathrm{g} / \mathrm{kg} / \mathrm{min}, \mathrm{P}=0.003)$. The interleukin- 6 and tumor necrosis factor- $\alpha$ concentrations at T1, T2, and T3 as well as the incidences of postoperative cardiac, pulmonary and kidney injuries were not different between the groups.

Conclusions: Ulinastatin pretreatment resulted in an improved oxygenation profile and reduced inotropic support, probably by attenuating the degree of cardiopulmonary injury; however, it did not reduce the levels of proinflammatory cytokines. (Korean J Anesthesiol 2013; 64: 334-340)

Key Words: Cardiopulmonary bypass, Inflammatory, Organ, Ulinastatin.

Received: June 15, 2012. Revised: 1st, July 14, 2012; 2nd, August 2, 2012; 3rd, October 8, 2012. Accepted: October 9, 2012.

Corresponding author: Tae-Yop Kim, M.D., Department of Anesthesiology, Konkuk University Medical Center, Research Institute of Biomedical Science, Konkuk University School of Medicine, 4-12, Hwayang-dong, Gwangjin-gu, Seoul 143-729, Korea. Tel: 82-2-2030-5445, Fax: 82-2-20305449, E-mail: taeyop@kuh.ac.kr

(C) This is an open-access article distributed under the terms of the Creative Commons Attribution Non-Commercial License (http:// creativecommons.org/licenses/by-nc/3.0/), which permits unrestricted non-commercial use, distribution, and reproduction in any medium, provided the original work is properly cited. 


\section{Introduction}

Cardiopulmonary bypass (CPB) and aortic cross-clamp (ACC) induce various perioperative inflammatory reactions and postoperative organ injury, contributing to postoperative organ dysfunction of heart, lungs, and kidneys after a cardiac surgery as well as increase perioperative morbidity and mortality. Upon exposure to the CPB circuit, circulating humoral and cellular factors activate neutrophils and the complement system to induce systemic inflammatory processes [1-3]. Consequently, analyses of serum inflammatory cytokines such as tumor necrosis factor (TNF)- $\alpha$ and interleukin (IL)- 6 have been used to determine the degree of systemic inflammation under various clinical conditions [3,4].

Many studies have examined the anti-inflammatory and protective effects of ulinastatin, a urinary trypsin inhibitor, against ischemia-reperfusion organ injury [5-7]. Their results indicate that ulinastatin suppresses neutrophil infiltration and reduces the release of elastase and chemical mediators produced by neutrophils [8-10]. Other clinical trials have described the inhibitory effects of ulinastatin on CPB-induced proinflammatory cytokine release and cardiopulmonary dysfunction, and stable hemodynamics during the post-CPB period [11-13]. However, those studies did not fully evaluate the positive effects of ulinastatin on postoperative organ dysfunction of the heart, lungs, and kidneys in relation to the attenuated release of proinflammatory cytokines during a cardiac surgery.

We hypothesized that ulinastatin pretreatment would attenuate CPB-induced inflammation and major organ injury. Therefore, in this study, we evaluated whether ulinastatin pretreatment would improve postoperative major organ function and attenuate proinflammatory cytokine release during a cardiac valve surgery.

\section{Materials and Methods}

After obtaining the approval from our Institutional Review Board, 30 patients undergoing an elective cardiac surgery were enrolled between March 2008 and December 2008. Informed consent was obtained from all subjects prior to the procedure. Preoperative exclusion criteria were: urgent/ emergency surgery, previous heart surgery, diabetes, ischemic heart disease, combined surgery with a coronary artery bypass graft procedure, age $>75$ years, left ventricular ejection fraction $<45 \%$, diabetes, active gastropathic disorder, chronic obstructive pulmonary disease, preoperative administration of furosemide, and renal failure requiring renal replacement therapy. The intraoperative exclusion criteria included: intraoperative use of an intra-aortic balloon pump (IABP), intraoperative administration of steroids or tranexamic acid, and intraoperative transfusion of fresh frozen plasma (FFP) or platelet concentrates during $\mathrm{CPB}$. The postoperative exclusion criteria included reoperation for surgical correction of an intractable postoperative bleeding within 2 hours after the end of surgery and transfusion of any banked blood product.

\section{Patient allocation}

Twenty-six patients undergoing elective cardiac surgery requiring $\mathrm{CPB}$ were assigned to a prospective, double-blinded, randomized fashion to two groups: control (group $\mathrm{C}, \mathrm{n}=13$ ) and ulinastatin pretreatment (group $U, n=13$ ) during our study period. Patients were allocated to the randomization process using a patient identification number, which was stratified in a $1: 1$ ratio, to receive either ulinastatin (Ulistin; Hallyim Inc., Markham, ON, Canada) or the same volume of normal saline. The investigators and physicians who managed the patients were blinded to the patients' group allocation. All physicians and nursing staff who cared for the patients were unaware of the group allocations. Ulinastatin $(5,000 \mathrm{U} / \mathrm{kg})$ or a placebo was administered intravenously $30-40 \mathrm{~min}$ before initiating CPB.

\section{Anesthesia and intensive care}

Preoperative medication continued until the morning of surgery. Upon patient arrival to an operating room, routine monitoring for cardiovascular surgical patients, including electrocardiogram (ECG), pulse oximetry, bispectral index (BIS; Aspect Medical System Inc., Norwood, MA, USA), and infrared regional cerebral $\mathrm{O}_{2}$ saturation (INVOS; Somanetics, Troy, MI, USA) were started.

After a $20-\mathrm{G}$ catheter was placed in the radial artery for continuous invasive arterial pressure monitoring, anesthesia was induced with a bolus of etomidate $(0.1-0.2 \mathrm{mg} / \mathrm{kg})$, a remifentanil infusion of $1.0 \mu \mathrm{g} / \mathrm{kg} / \mathrm{min}$, and a target-controlled infusion of propofol (effect-site concentration, $1.0-1.5 \mu \mathrm{g} / \mathrm{ml}$ ) in all patients. Next, the propofol target concentration was adjusted to maintain a BIS score of 45-60. Tracheal intubation and intraoperative muscle relaxation were facilitated and maintained by a bolus and supplemental administration of rocuronium under the guidance of peripheral nerve stimulator monitoring. After tracheal intubation, patients were mechanically ventilated with volume-controlled ventilation using an oxygen/air mixture $\left(\mathrm{FiO}_{2}\right)$ of 0.5 at a fixed tidal volume of $8 \mathrm{ml} / \mathrm{kg}$. The respiration rate was adjusted to maintain an end-tidal carbon dioxide tension of 35-40 $\mathrm{mmHg}$.

After inducing anesthesia, a large-bore central venous and pulmonary artery catheter were placed in the internal jugular vein to monitor central venous pressure (CVP), pulmonary 
arterial pressure (PAP), continuous cardiac output, and mixed venous $\mathrm{O}_{2}$ saturation $\left(\mathrm{SvO}_{2}\right)$. A transesophageal echocardiography (TEE) probe (Omniplane and Vivid 7; GE Healthcare, Piscataway, NJ, USA) was inserted, and comprehensive TEE was performed. Prior to $\mathrm{CPB}$, the mean arterial blood pressure (MABP) was maintained at $80-120 \%$ of the pre-induction value in all patients throughout the entire study period using hydroxyethylstarch $(100-250 \mathrm{ml})$ and phenylephrine $(0.01-$ $0.06 \mu \mathrm{g} / \mathrm{kg} / \mathrm{min})$.

Ulinastatin $(5,000 \mathrm{U} / \mathrm{kg})$ or the same volume of normal saline (placebo) was intravenously administered to group $\mathrm{U}$ or $\mathrm{C}$, respectively, over $10 \mathrm{~min}$ after the opening of a pericardium.

Heparin (300 IU/kg) was infused to maintain an activated coagulation time of $>450$ s during $\mathrm{CPB}$. The extracorporeal circuit was primed with $1,500 \mathrm{ml}$ of crystalloid solution consisting of 1,300 ml of balanced solution, $100 \mathrm{ml}$ of $20 \%$ mannitol, and $100 \mathrm{ml}$ of $20 \%$ albumin. A membrane oxygenator with hollow polypropylene fibers and polyvinyl chloride tubing was used for CPB. The low flow rates during CPB were adjusted to $2.2-2.5 \mathrm{~L} / \mathrm{min} / \mathrm{m}^{2}$ to maintain a systemic perfusion pressure of 60-70 mmHg. Phenylephrine was administered when necessary to maintain the target systemic pressure. A mild to moderate hypothermic $\mathrm{CPB}$ technique $\left(26-28^{\circ} \mathrm{C}\right)$ was applied during $\mathrm{CPB}$, and the hematocrit was maintained at $23-25 \%$, but warm modified cardioplegic reperfusion was performed before release of the cross-clamp. Packed red blood cells were transfused in cases of a low hematocrit $(<21 \%)$. Myocardial protection was achieved by inducing intermittent antegrade and retrograde cold $\left(4^{\circ} \mathrm{C}\right)$ crystalloid cardioplegia every 30 minutes and continuous topical cooling during cardiac standstill. $\mathrm{PaCO}_{2}$ was maintained at $40 \mathrm{mmHg}$ at the standard electrode temperature of $37^{\circ} \mathrm{C}$ ( $\alpha$-stat) during CPB. The patients were weaned from $\mathrm{CPB}$ when their rectal temperature reached $36^{\circ} \mathrm{C}$. Heparin was neutralized with protamine sulfate.

Intraoperative fluid management was performed upon a routine TEE monitoring of two-dimensional cardiac contour images and Doppler profiles. Dopamine was infused as a firstline inotropic agent to wean the patients from $\mathrm{CPB}$ when the rectal temperature was $>35^{\circ} \mathrm{C}$ in all patients. The dopamine infusion rate was adjusted to achieve a cardiac index $(\mathrm{CI})$ $>2.0 \mathrm{~L} / \mathrm{min} / \mathrm{m}^{2}$ and MABP $>65 \mathrm{mmHg}$ and continues until full restoration of sufficient hemodynamics without inotropic support.

After the surgery, the patients were taken to the intensive care unit (ICU) and ventilated with institutional routine ventilation with a $\mathrm{FiO}_{2}$ of $0.3-0.5$. The patients were weaned off mechanical ventilation as soon as they were awake and breathing faster than the ventilator set rate and extubated when they met the extubation criteria.

\section{Data collection and blood sampling}

The following intraoperative variables were determined immediately after anesthesia induction (T1), 1 hour after weaning from CPB (T2), and at the end of surgery (T3): CI, MABP, CVP, mean PAP, heart rate, mixed venous oxygen saturation, serum lactate, hematocrit, arterial $\mathrm{O}_{2}$ tension $\left(\mathrm{PaO}_{2}\right)$, arterial $\mathrm{O}_{2}$ tension/ inspired $\mathrm{O}_{2}$ ratio $\left(\mathrm{PaO}_{2} / \mathrm{FiO}_{2}\right.$ ratio), and $\mathrm{BIS}$. Dopamine infusion less than 5 minutes was excluded from the determination of the dopamine requirement.

Creatine kinase-MB (CK-MB), troponin I (TnI), and serumcreatinine ( $\mathrm{s}-\mathrm{Cr}$ ) were measured before the induction of anesthesia (T0) and immediately after the end of anesthesia (T3).

Postoperative blood analysis was performed at 24 hours after the completion of the surgery (POD).

The patients' plasma levels of IL- 6 and TNF- $\alpha$ were determined at T1, T2, and T3. Blood samples were drawn into the tubes containing ethylenediaminetetraacetic acid via the central venous catheter and centrifuged at 3,000 rpm for $20 \mathrm{~min}$. The extracted plasma was stored in polypropylene tubes at $-80^{\circ} \mathrm{C}$ until further analysis and then analyzed for IL- 6 and TNF- $\alpha$ by a quantitative sandwich enzyme immunoassay (Quantikine ELISA; R\&D Systems, Inc., Minneapolis, MN, USA). All enzyme immunoassays were performed with a V-MAX 220 VAC ELISA reader (Molecular Devices, Palo Alto, CA, USA).

For primary objectives, $\mathrm{PaO}_{2} / \mathrm{FiO}_{2}$, CK-MB, TnI, the glomerular filtration rate (GFR), and creatinine $(\mathrm{Cr})$ clearance were recorded at POD to determine the degree of postoperative major organ dysfunction and their intergroup differences were determined.

The $\mathrm{PaO}_{2} / \mathrm{FiO}_{2}$ ratio, dopamine requirement, and s-Cr were recorded at T3. The incidence of postoperative myocardial, pulmonary, or renal injury was defined as: elevated TnI $(>0.68 \mu \mathrm{g} / \mathrm{l})$ and CK-MB $(>40.4 \mu \mathrm{g} / \mathrm{l})$ with a newly developed pathological Q wave on ECG (13); $\mathrm{PaO}_{2} / \mathrm{FiO}_{2}$ ratio $<3.0$ with bilateral pulmonary infiltration on the chest radiography without clinical evidence of elevated left atrial pressure; and an increase in s-Cr of $>0.3 \mathrm{mg} / \mathrm{dl}$ or $50 \%$ from baseline within 48 hours as defined by the Acute Kidney Injury Network (AKIN) [14] or urine output $<0.5 \mathrm{ml} / \mathrm{kg} / \mathrm{h}$ for $>6 \mathrm{hrs}$ despite of fluid resuscitation within 24 hours after surgery.

\section{Data analysis}

Statistical analyses were performed with SPSS software (Chicago, IL, USA). All values are reported as the mean (standard deviation and $95 \%$ confidence interval [CI]) for normally distributed variables or median $\left(25-75^{\text {th }}\right.$ percentile) if the distribution was not normal. Unpaired Student's t-tests or the Mann-Whitney U-test were used for intergroup comparisons of the mean or median values. The Fisher's exact test was 
used to analyze intergroup differences in the categorical data, including the incidences. A two-way repeated-measures analysis of variance (ANOVA) was used to compare serially recorded variables. If a difference was found, the Student's t-test (or the Mann-Whitney U-test, as appropriate) was used for an intergroup comparison. Repeated-measures one-way ANOVA or Friedman's test were used followed by Dunnett's or Tukey's tests for multiple pairwise comparisons versus $\mathrm{T} 1$ values. Statistical significance was set at $\mathrm{P}<0.05$.

A minimum sample size of 10 in each group was necessary to produce an intergroup and intragroup difference of mean $\mathrm{PaO}_{2} /$ $\mathrm{FiO}_{2}$ ratio $>116.4$ (30\% of mean $\mathrm{PaO}_{2} / \mathrm{FiO}_{2}$ ratio, 388.0) with an expected standard difference of 74.7 , a power of 0.80 and an alpha of 0.05 , based on our pilot data which were previously

Table 1. Demographic Data

\begin{tabular}{lcc}
\hline & Group C (n=11) & Group U (n=13) \\
\hline Age (yr) & $59 \pm 15$ & $58 \pm 17$ \\
Sex (M/F) & $6 / 5$ & $4 / 7$ \\
Height (cm) & $163.8 \pm 11.8$ & $162.8 \pm 7.8$ \\
Body weight (kg) & $61.9 \pm 12.8$ & $60.3 \pm 5.0$ \\
Body surface area $\left(\mathrm{m}^{2}\right)$ & $1.63 \pm 0.25$ & $1.38 \pm 0.62$ \\
Type of surgery & & \\
Mitral valve repair & 5 & 4 \\
Aortic valve repair & 3 & 5 \\
Tricuspid valve repair & 1 & 0 \\
Pulmonary valve repair & 0 & 1 \\
Double valve repair & 2 & 3 \\
Preoperative medications & & 3 \\
$\quad$ Digoxin & 3 & 3 \\
Calcium channel blocker & 4 & 1 \\
Angiotensin receptor blocker & 3 & $4.35 \pm 0.39$ \\
s-albumin (mg) & $4.17 \pm 0.39$ & $0.91 \pm 0.23$ \\
s-creatinine (mg/dl) & $1.01 \pm 0.15$ &
\end{tabular}

All values are the mean \pm standard deviation or number of patients. No significant intergroup differences are observed. Group U: patients treated with intravenous ulinastatin 5,000 U/ $\mathrm{kg}$, Group C: patients treated with placebo. corrected from 10 previous cardiac surgery patients as baseline values.

\section{Results}

Two patients were excluded from group $\mathrm{C}$ and one patient was excluded from group $U$ due to the intraoperative administration of tranexamic acid, IABP insertion, and transfusion of FFP or platelet concentrate during CPB.

Demographic data and preoperative and intraoperative interventions such as CPB time, ACC time, and amount of banked blood transfused were not different between the groups, except for intraoperative urine output $(\mathrm{P}=0.017)$ (Table 1 and 2).

As primary outcomes, the $\mathrm{PaO}_{2} / \mathrm{FiO}_{2}$ ratio at POD in group $\mathrm{U}(3.9 \pm 0.6)$ was significantly higher than that in group $\mathrm{C}(2.9$ $\pm 0.6)(\mathrm{P}=0.001)$. CK-MB at POD in group $\mathrm{U}$ was significantly lower than that in group $\mathrm{C}(\mathrm{P}=0.030)$, but $\mathrm{TnI}$ at $\mathrm{POD}$ was not

Table 2. Intraoperative Interventions

\begin{tabular}{lrcc}
\hline & $\begin{array}{r}\text { Group C } \\
(\mathrm{n}=11)\end{array}$ & $\begin{array}{c}\text { Group U } \\
(\mathrm{n}=13)\end{array}$ & $\mathrm{P}$ \\
\hline CPB time (min) & $139 \pm 42$ & $150 \pm 44$ & 0.527 \\
ACC time (min) & $91 \pm 44$ & $104 \pm 39$ & 0.463 \\
Transfusion during CPB & $2(0-3)$ & $2(0-2)$ & \\
packed red blood cells (unit) & & & \\
Transfusion during post-CPB & $1(0-1)$ & $0(0-0)$ & \\
period platelet (unit) & & & \\
FFP (unit) & $2(0.75-3)$ & $2(0-2)$ & \\
Dopamine requirement ( $\mu \mathrm{g} / \mathrm{kg} / \mathrm{min})$ & $5.5 \pm 3.3$ & $1.6 \pm 1.6$ & 0.003 \\
Urine output (ml/h) & $119 \pm 67$ & $190 \pm 60$ & 0.017
\end{tabular}

All values are the mean standard \pm deviation or median $\left(25-75^{\text {th }}\right.$ percentile). CPB time: duration of cardiopulmonary bypass (CPB) application, ACC time: duration for application of the aortic-cross clamp (ACC), Dopamine requirement: mean dopamine infusion rate during the CPB period, Platelet: platelet concentrate (platelet 1 unit was comparable to 6 units of multi-donor platelet concentrate available in Korea), FFP: fresh frozen plasma.

Table 3. Postoperative Outcomes

\begin{tabular}{|c|c|c|c|}
\hline & Group C $(\mathrm{n}=11)$ & Group $U(n=13)$ & $\mathrm{P}$ \\
\hline $\mathrm{PaO}_{2} / \mathrm{FiO}_{2}$ ratio & $271.9 \pm 29.4$ & $398.2 \pm 70.3$ & $<0.001$ \\
\hline CK-MB (ng/ml) & $33.7 \pm 22.1$ & $17.7 \pm 7.3$ & 0.030 \\
\hline $\operatorname{TnI}(\mathrm{ng} / \mathrm{ml})$ & $7.8 \pm 6.2$ & $4.8 \pm 3.2$ & 0.160 \\
\hline $\mathrm{s}-\mathrm{Cr}(\mathrm{mg} / \mathrm{dl})$ & $1.34 \pm 0.50$ & $1.10 \pm 0.26$ & 0.153 \\
\hline $\operatorname{GFR}\left(\mathrm{ml} / \mathrm{min} / 1.73 \mathrm{~m}^{2}\right)$ & $52.2 \pm 15.5$ & $61.6 \pm 17.4$ & 0.195 \\
\hline $\mathrm{CrCl}(\mathrm{ml} / \mathrm{min})$ & $55.5 \pm 15.6$ & $66.8 \pm 19.8$ & 0.155 \\
\hline Extubation time (min) & $525(366-378)$ & $550(462-766)$ & 0.948 \\
\hline Urine output in the first $2 \mathrm{~h}$ in the ICU $(\mathrm{ml})$ & $429 \pm 179$ & $572 \pm 293$ & 0.182 \\
\hline Bleeding during the first $2 \mathrm{~h}$ in the ICU (chest tube, $\mathrm{ml}$ ) & $73 \pm 54$ & $128 \pm 166$ & 0.330 \\
\hline
\end{tabular}

All values are the mean \pm standard deviation or median $\left(25-75^{\text {th }}\right.$ percentile). Group U: patients treated with intravenous ulinastatin 5,000 U/ $\mathrm{kg}$, Group C: patients treated with placebo. $\mathrm{PaO}_{2} / \mathrm{FiO}_{2}$ ratio: arterial $\mathrm{O}_{2}$ tension/inspired $\mathrm{O}_{2}$ ratio measured at 24 hr after the end of surgery, CKMB: creatine kinase-MB, TnI: tropoine I, s-Cr: serum creatinine, GFR: glomerular filtration rate, $\mathrm{CrCl}$ : creatinine clearance $=(140-$ age $) \times$ ideal body weight $/(\mathrm{s}-\mathrm{Cr} \times 72)(\times 0.85$ in female patients $)$ extubation time, duration from the admission to the intensive care unit (ICU). 
different between the groups. s-Cr, the estimated GFR, and $\mathrm{Cr}$ clearance at POD were not different between the groups (Table 3).

The intraoperative $\mathrm{PaO}_{2} / \mathrm{FiO}_{2}$ ratio and $\mathrm{PaO}_{2} / \mathrm{FiO}_{2}$ ratio at $\mathrm{T} 1$ and $\mathrm{T} 2$ were not different between the groups, but that at T3 in group $\mathrm{U}(3.8 \pm 0.8,95 \% \mathrm{CI}, 3.4-4.2)$ was significantly greater than that in group C $(2.8 \pm 0.7 ; 95 \% \mathrm{CI}, 2.4-3.3, \mathrm{P}=0.005)$.

Table 4. Changes in the Intraoperative Parameters

\begin{tabular}{|c|c|c|c|c|}
\hline & & $\begin{array}{l}\text { Group C } \\
(n=11)\end{array}$ & $\begin{array}{l}\text { Group U } \\
(n=13)\end{array}$ & $\mathrm{P}$ \\
\hline \multirow[t]{3}{*}{$\mathrm{CI}\left(\mathrm{L} / \mathrm{min} / \mathrm{m}^{2}\right)$} & $\mathrm{T} 1$ & $2.8 \pm 0.7$ & $2.7 \pm 0.5$ & 0.554 \\
\hline & $\mathrm{T} 2$ & $3.2 \pm 0.7$ & $3.1 \pm 0.5$ & 0.882 \\
\hline & T3 & $3.5 \pm 0.9$ & $2.9 \pm 0.5$ & 0.312 \\
\hline \multirow[t]{3}{*}{ MBP (mmHg) } & $\mathrm{T} 1$ & $68 \pm 6$ & $76 \pm 10$ & 0.053 \\
\hline & $\mathrm{T} 2$ & $70 \pm 7$ & $70 \pm 8$ & 0.926 \\
\hline & T3 & $70 \pm 8$ & $71 \pm 8$ & 0.242 \\
\hline \multirow[t]{3}{*}{ CVP (mmHg) } & $\mathrm{T} 1$ & $8 \pm 4$ & $8 \pm 2$ & 0.933 \\
\hline & $\mathrm{T} 2$ & $11 \pm 3$ & $11 \pm 3$ & 0.987 \\
\hline & T3 & $12 \pm 4$ & $12 \pm 3$ & 1.000 \\
\hline \multirow[t]{3}{*}{ MPAP (mmHg) } & $\mathrm{T} 1$ & $21 \pm 5$ & $17 \pm 4$ & 0.232 \\
\hline & $\mathrm{T} 2$ & $24 \pm 8$ & $23 \pm 8$ & 0.878 \\
\hline & T3 & $25 \pm 8$ & $23 \pm 8$ & 0.520 \\
\hline \multirow[t]{3}{*}{ HR (beats/min) } & $\mathrm{T} 1$ & $71 \pm 16$ & $76 \pm 16$ & 0.101 \\
\hline & $\mathrm{T} 2$ & $86 \pm 16$ & $85 \pm 10$ & 0.227 \\
\hline & T3 & $83 \pm 18$ & $83 \pm 13$ & 0.093 \\
\hline \multirow[t]{3}{*}{$\mathrm{SvO}_{2}(\%)$} & $\mathrm{T} 1$ & $79.9 \pm 3.2$ & $76.5 \pm 5.7$ & 0.103 \\
\hline & $\mathrm{T} 2$ & $80.6 \pm 4.4$ & $78.0 \pm 5.7$ & 0.485 \\
\hline & $\mathrm{T} 3$ & $80.5 \pm 5.0$ & $77.3 \pm 5.7$ & 0.197 \\
\hline \multirow[t]{3}{*}{ Lactate (mmol/l) } & $\mathrm{T} 1$ & $0.86 \pm 0.27$ & $1.14 \pm 0.48$ & 0.114 \\
\hline & $\mathrm{T} 2$ & $2.29 \pm 1.23$ & $2.97 \pm 0.78$ & 0.136 \\
\hline & $\mathrm{T} 3$ & $1.43 \pm 0.91$ & $1.96 \pm 1.38$ & 0.303 \\
\hline \multirow[t]{3}{*}{$\mathrm{PaO}_{2} / \mathrm{FiO}_{2}$ ratio } & $\mathrm{T} 1$ & $411.3 \pm 72.7$ & $412.1 \pm 107.8$ & 0.984 \\
\hline & $\mathrm{T} 2$ & $290.9 \pm 86.8$ & $357.3 \pm 131.8$ & 0.167 \\
\hline & T3 & $281.6 \pm 73.8$ & $397.2 \pm 80.2$ & 0.005 \\
\hline \multirow[t]{3}{*}{ BIS } & $\mathrm{T} 1$ & $46.2 \pm 4.1$ & $43.9 \pm 5.2$ & 0.028 \\
\hline & $\mathrm{T} 2$ & $46.4 \pm 8.4$ & $42.3 \pm 3.0$ & 0.690 \\
\hline & T3 & $46.3 \pm 7.6$ & $43.3 \pm 4.7$ & 0.844 \\
\hline
\end{tabular}

All values are the mean \pm standard deviation. Group U: patients treated with intravenous ulinastatin 5,000 U/ $\mathrm{kg}$, Group C: patients treated with placebo. T1: after anesthesia induction, T2: $1 \mathrm{hr}$ after weaning from $\mathrm{CPB}$, and T3: atthe end of surgery. CI: cardiac index, MBP: mean arterial BP, CVP: central venous pressure, MPAP: mean pulmonary arterial $\mathrm{BP}, \mathrm{HR}$ : heart rate, $\mathrm{SvO}_{2}$ : mixed venous oxygen saturation Lactate, serum lactate level, $\mathrm{PaO}_{2} / \mathrm{FiO}_{2}$ ratio: arterial $\mathrm{O}_{2}$ tension/inspired $\mathrm{O}_{2}$ ratio, and BIS: bispectral index score.
The dopamine requirement during post-CPB in group $U$ was significantly less than that in group $\mathrm{C}(\mathrm{P}=0.003)$ (Table 4).

The intraoperative levels of IL- 6 and TNF- $\alpha$ at T2 and T3 were significantly greater than those at $\mathrm{T} 1$ in both groups, but those at T1, T2, and T3 were not different between the groups (Table 5).

Postoperative urine output was not different between the groups. The incidence of pulmonary injury, myocardial injury, and AKIN was also not different between the groups (Table 6).

\section{Discussion}

This study showed that ulinastatin pretreatment, even at a low dosage $(5,000 \mathrm{IU} / \mathrm{kg})$, resulted in better pulmonary function with a significantly higher postoperative $\mathrm{PaO}_{2} / \mathrm{FiO}_{2}$ ratio and less myocardial injury with a significantly less elevated postoperative CK-MB level. Furthermore, ulinastatin provided better cardiac performance requiring less inotropic support and a higher $\mathrm{PaO}_{2} / \mathrm{FiO}_{2}$ ratio after weaning from CPB. Our results suggest that a small pretreatment dose of ulinastatin provides more favorable postoperative cardiopulmonary function after applying $\mathrm{CPB}$, in accordance with the previous clinical studies showing favorable clinical profiles. Ulinastatin does not suppress norepinephrine release or post-CPB myocardial enzyme release [14]; however, it provides a more favorable

Table 6. Incidence of Postoperative Organ Dysfunction

\begin{tabular}{lccc}
\hline & Group C $(\mathrm{n}=11)$ & Group U $(\mathrm{n}=13)$ & $\mathrm{P}$ \\
\hline Pulmonary injury & 3 & 7 & 0.236 \\
Myocardial injury & 5 & 2 & 0.182 \\
Kidney injury & 4 & 4 & 1.000 \\
\hline
\end{tabular}

All values are the number of patients. Pulmonary injury was defined as $\mathrm{PaO}_{2} / \mathrm{FiO}_{2}$ ratio $<300$ with bilateral pulmonary infiltration on chest radiography without clinical evidence of elevated left atrial pressure. Myocardial injury was defined as an elevation in troponin I ( $>6.8 \mathrm{ng} / \mathrm{ml})$ and creatine kinase-MB ( $>40.4 \mathrm{ng} / \mathrm{ml})$ with a newly developed pathologic $\mathrm{Q}$ wave on electrocardiogram. Kidney injury was defined as an increase in serum creatinine $>0.3 \mathrm{mg} / \mathrm{dl}$ or $50 \%$ from preoperative values within $48 \mathrm{hr}$ when applicable. Fisher's exact test was used for intergroup comparisons.

Table 5. Intraoperative Proinflammatory Cytokine Levels

\begin{tabular}{lcccc}
\hline & & Group C $(\mathrm{n}=11)$ & Group U (n= 13) & P \\
\hline IL-6 $(\mathrm{pg} / \mathrm{ml})$ & T1 & $1.51(1.9-2.0)$ & $0.07(0.07-1.34)$ & 0.023 \\
& T2 & $251.1(103.5-300.0)$ & $184.9(69.9-300.0)$ & 0.554 \\
TNF- $\alpha$ (pg-ml) & T3 & $123.0(61.8-150.2)$ & $106.6(38.9-123.9)$ & 0.941 \\
& T1 & $1.6(1.4-3.7)$ & $0.9(0.5-1.3)$ & 0.075 \\
& T2 & $4.4(3.3-6.4)$ & $6.3(1.8-8.7)$ & 0.743 \\
& T3 & $1.6(1.1-2.0)$ & $1.7(1.5-3.0)$ & 0.307 \\
\hline
\end{tabular}

All values are the median $\left(25-75^{\text {th }}\right.$ percentile). Group U: patients treated with intravenous ulinastatin 5,000 U/kg, Group C: patients treated with placebo. T1: after anesthesia induction, T2: $1 \mathrm{hr}$ after weaning from CPB, and T3: at the end of surgery. IL-6: interleukin-6, TNF- $\alpha$ : tumor necrosis factor- $\alpha$. 
postoperative lung function [15]. Ulinastatin administration before CPB improves cardiovascular stability and pulmonary dysfunction, whereas it does not suppress the CPB-induced release of neutrophils or increase myocardial enzyme levels [11]. The increased $\mathrm{PaO}_{2} / \mathrm{FiO}_{2}$ ratio following ulinastatin pretreatment suggests a reduction in postoperative morbidity and mortality as shown in other studies [16-18].

Ulinastatin pretreatment did not affect other outcomes, including intraoperative and postoperative renal function or the amount of postoperative bleeding thorough a chest tube in this study. The absence of an intergroup difference in the postoperative TnI level, a more specific indicator of myocardial injury, may contradict the efficacy of ulinastatin for attenuating myocardial injury and providing a favorable cardiac function, which were indicated by the reduced release of CK-MB and reduced the need for inotropic support in our study.

However, we did not find any attenuation of proinflammatory cytokines, including TNF- $\alpha$ and IL-6, in the ulinastatin-treated group. This negative result complicates the analysis of the wellknown causal relationship between CPB-induced systemic inflammation and resulting organ injury and dysfunction during cardiac surgery. CPB produces multiple organ injury and dysfunction; it activates neutrophils and circulating adhesion molecules. These activated neutrophils can cause various organ injuries by adhering to myocytes and the endothelium and by releasing a variety of cell-activating and cytotoxic substances, including potent activators of complements and cytokines, and initial systemic inflammatory triggers such as IL-6, IL-8, TNF- $\alpha$, and endotoxins [17-23]. However, our result corresponded to those of a previous study showing that plasma IL- 6 and TNF- $\alpha$ did not increase after $\mathrm{CPB}$, despite a considerable increase in plasma IL-8. That study also showed a preferential increase of gene expressions for IL-6, IL-8, and TNF- $\alpha$ in airway spaces (alveolar macrophages) rather than in plasma (plasma monocytes). The post-CPB increase in airway proinflammatory cytokines was up to eight times greater than that in plasma, suggesting that CPB preferentially produces an inflammatory response in the lungs [24]. Nakanishi et al. [11] insisted that IL-8 is much more closely related with lung function and can be used to predict postCPB oxygenation profiles, whereas IL-6 is closely related with myocardial function.

These results may justify the absence of an intergroup difference in the IL- 6 level in the present study despite the greater $\mathrm{PaO}_{2} / \mathrm{FiO}_{2}$ ratio, and an analysis of cytokines in alveolar macrophages may be required to clarify the efficacy of ulinastatin for attenuating the inflammatory reaction and pulmonary injury.

Bingyang et al. [15] suggested that a higher dosage (400,000 $\mathrm{U})$ and a longer ulinastatin infusion period are required for better postoperative organ function and reduced release of
CPB-induced proinflamatory cytokines. The relatively short half-life of ulinastin (33 min after a 3 -h infusion) compared to the duration of CPB (60 $\mathrm{min}$ ) in this study may have been insufficient to cover the entire $\mathrm{CPB}$ period and to attenuate the CPB-induced inflammatory process [14].

We excluded high-risk patients with more frequent and exaggerated post-CPB myocardial or pulmonary dysfunction in whom the possible efficacy of ulinastatin may be more prominent. To overcome this mismatch and to assess the possible efficacy of ulinastatin for attenuating the CPB-induced release of proinflammatory cytokines, further study using a much higher dosage and longer infusion of ulinastatin is indicated. Furthermore, as the sample size focused on improving the oxygenation profile, it may have been insufficient to speculate the other parameters as secondary outcomes in this study. Thus, additional trials with a much larger sample size are advocative.

In conclusion, $\mathrm{CPB}$ pretreatment with ulinastatin resulted in less cardiopulmonary injuries and better cardiac pulmonary performance during the post-CPB period, as indicated by an improved oxygenation profile and reduced inotropic support; however, it did not attenuate the CPB-induced release of proinflammatory cytokines. Additional studies adopting a much higher ulinastatin dosage during the entire period, a larger sample size, and an airway cytokine analysis are necessary to confirm the efficacy of ulinastatin to attenuate the CPB-induced release of inflammatory cytokines and to enhance post-CPB organ function.

\section{Acknowledgments}

This study was supported by Konkuk University Medical Center Grant 2010.

This study was presented in a part in the Annual Meeting of the Korean Society of Cardiothoracic and Vascular Anesthesiologits in 2009.

\section{References}

1. Ito H, Hamano K, Gohra H, Katoh T, Fujimura Y, Tsuboi H, et al. Relationship between respiratory distress and cytokine response after cardiopulmonary bypass. Surg Today 1997; 27: 220-5.

2. Picone AL, Lutz CJ, Finck C, Carney D, Gatto LA, Paskanik A, et al. Multiple sequential insults cause post-pump syndrome. Ann Thorac Surg 1999; 67: 978-85.

3. Laffey JG, Boylan JF, Cheng DC. The systemic inflammatory response to cardiac surgery: implications for the anesthesiologist. Anesthesiology 2002; 97: 215-52.

4. Kawamura T, Wakusawa R, Okada K, Inada S. Elevation of cytokines during open heart surgery with cardiopulmonary bypass: participation of interleukin 8 and 6 in reperfusion injury. Can J Anaesth 1993; 40: 1016-21. 
5. Nakahama H, Obata K, Sugita M. Ulinastatin ameliorates acute ischemic renal injury in rats. Ren Fail 1996; 18: 893-8.

6. Ren B, Wu H, Zhu J, Li D, Shen Y, Ying R, et al. Ulinastatin attenuates lung ischemia-reperfusion injury in rats by inhibiting tumor necrosis factor alpha. Transplant Proc 2006; 38: 2777-9.

7. Cao ZL, Okazaki Y, Naito K, Ueno T, Natsuaki M, Itoh T. Ulinastatin attenuates reperfusion injury in the isolated blood-perfused rabbit heart. Ann Thorac Surg 2000; 69: 1121-6.

8. Hirose J, Ozawa T, Miura T, Isaji M, Nagao Y, Yamashiro K, et al. Human neutrophil elastase degrades inter-alpha-trypsin inhibitor to liberate urinary trypsin inhibitor related proteins. Biol Pharm Bull 1998; 21: 651-6.

9. Endo S, Inada K, Yamashita H, Takakuwa T, Nakae H, Yamada Y, et al. The inhibitory actions of protease inhibitors on the production of polymorphonuclear leukocyte elastase and interleukin 8 . Res Commun Chem Pathol Pharmacol 1993; 82: 27-34.

10. Nakatani K, Takeshita S, Tsujimoto H, Kawamura Y, Sekine I. Inhibitory effect of serine protease inhibitors on neutrophilmediated endothelial cell injury. J Leukoc Biol 2001; 69: 241-7.

11. Nakanishi K, Takeda S, Sakamoto A, Kitamura A. Effects of ulinastatin treatment on the cardiopulmonary bypass-induced hemodynamic instability and pulmonary dysfunction. Crit Care Med 2006; 34: 1351-7.

12. Hiyama A, Takeda J, Kotake Y, Morisaki H, Fukushima K. A human urinary protease inhibitor (ulinastatin) inhibits neutrophil extracellular release of elastase during cardiopulmonary bypass. J Cardiothorac Vasc Anesth 1997; 11: 580-4.

13. Oh SY, Kim JC, Choi YS, Lee WK, Lee YK, Kwak YL. Effects of ulinastatin treatment on myocardial and renal injury in patients undergoing aortic valve replacement with cardiopulmonary bypass. Korean J Anesthesiol 2012; 62: 148-53.

14. Jönsson-Berling BM, Ohlsson K. Distribution and elimination of intravenously injected urinary trypsin inhibitor. Scand J Clin Lab Invest 1991; 51: 549-57.

15. Bingyang J, Jinping L, Mingzheng L, Guyan W, Zhengyi F. Effects of urinary protease inhibitor on inflammatory response during on-pump coronary revascularisation. Effect of ulinastatin on inflammatory response. J Cardiovasc Surg (Torino) 2007; 48: 497503.

16. Rady MY, Ryan T, Starr NJ. Early onset of acute pulmonary dysfunction after cardiovascular surgery: risk factors and clinical outcome. Crit Care Med 1997; 25: 1831-9.

17. Asimakopoulos G, Smith PL, Ratnatunga CP, Taylor KM. Lung injury and acute respiratory distress syndrome after cardiopulmonary bypass. Ann Thorac Surg 1999; 68: 1107-15.

18. Ng CS, Wan S, Yim AP, Arifi AA. Pulmonary dysfunction after cardiac surgery. Chest 2002; 121: 1269-77.

19. Morse DS, Adams D, Magnani B. Platelet and neutrophil activation during cardiac surgical procedures: impact of cardiopulmonary bypass. Ann Thorac Surg 1998; 65: 691-5.

20. Pallua N, Low JF, von Heimburg D. Pathogenic role of interleukin-6 in the development of sepsis. Part II: Significance of antiinterleukin-6 and anti-soluble interleukin-6 receptor-alpha antibodies in a standardized murine contact burn model. Crit Care Med 2003; 31 : 1495-501.

21. Shalaby MR, Waage A, Aarden L, Espevik T. Endotoxin, tumor necrosis factor-alpha and interleukin 1 induce interleukin 6 production in vivo. Clin Immunol Immunopathol 1989; 53: 488-98.

22. Beutler B, Cerami A. The biology of cachectin/TNF--a primary mediator of the host response. Annu Rev Immunol 1989; 7: 625-55.

23. Andersen LW, Landow L, Baek L, Jansen E, Baker S. Association between gastric mucosal $\mathrm{pH}$ and splanchnic endotoxin, antibody to endotoxin, and tumor necrosis factor-alpha concentrations in patients undergoing cardiopulmonary bypass. Crit Care Med 1993; 21: 210-7.

24. Kotani N, Hashimoto H, Sessler DI, Muraoka M, Wang JS, O'Connor MF, et al. Cardiopulmonary bypass produces greater pulmonary than systemic proinflammatory cytokines. Anesth Analg 2000; 90: 1039-45. 